Supporting information:

\title{
Preparation of Thermally Imidized Polyimide Nanofiltration Membranes with Macrovoid-Free Structures
}

Yuan Li, Rui Yang, Rui Zhang, Bing Cao and Pei Li*

College of Materials Science and Engineering, Beijing University of Chemical Technology, Beijing, 100029, China.

*Corresponding author. E-mail address: lipei@mail.buct.edu.cn (P. Li);

\section{Impact of pore structure on mechanical properties}

Asymmetric nanofiltration membrane typically has a dense skin layer determining separation property (flux and selectivity) and a thick porous supporting layer providing mechanical strength [1]. Since mechanic properties are relevant to membrane porosity, distribution and inter-connectivity of pores, many researchers have built models to correlate pore structures and mechanical properties [1-6]. Yung [3] introduced a model to describe relation between fractural strain and porosity of porous material as shown in equation (1):

$$
\varepsilon_{f}=\frac{2 \sigma_{m} r_{p}}{\rho E_{m}}\left[\left(\frac{2 \pi}{3 f_{p}}\right)^{\frac{1}{2}}-\frac{\pi}{2}\right]
$$

where $\varepsilon_{f}, \sigma_{m}, r_{p}, f_{p}$ and $E_{m}$ were fractural strain, yield stress, mean pore radius, porosity and elastic modulus of material, respectively. However, this model is empirical and only valid at low void fraction with uniformly-distributed pore structure. Membrane often has porosity over $50 \%$ and large pores such as finger-like macrovoids. And pore collapsing take places under a much lower stress than the yield stress of the bulk polymer. This is because stress concentration is 
generated at wall of pores $[4,7]$. Thus, size distribution and inter-connectivity of pores are also essential factors to mechanical property. Evans and Tappin [6] established a model to describe pore crack process using equation (2):

$$
\sigma=\frac{\pi}{2}\left(\frac{\beta}{\tan \beta} \frac{\frac{1}{2} \sigma_{p}}{\sigma_{c}}\left(\frac{E \gamma}{R+L}\right)^{\frac{1}{2}}\right.
$$

where $\sigma$ was the minimal stress to induce pore crack; $\beta=\pi R /(2 R+\lambda)$; $R$ was mean radius of pores; $\lambda$ was mean distance between two nearest pores (i.e. pore spacing); $L$ was the length of emanating fissure on cracks; E was the Young's Modulus of material; $\gamma$ was fracture energy; $\delta_{\mathrm{p}} / \delta_{\mathrm{c}}$ was ratio of stress of propagate a crack with dimensions $\mathrm{R}$ to that with dimensions $\mathrm{R}+\mathrm{L}$. To simplify this formula, for brittle materials (e.g. polyimide), plastic deformation is subtler. Thus, $\mathrm{R}+\mathrm{L} \approx \mathrm{R}$, $\delta_{\mathrm{p}} / \delta_{\mathrm{c}} \approx 1$. When comparing mechanical strengths of membranes based on the same polymer, E and $\gamma$ are constant. Note that, the critical threshold to determine an open or close pore is $\lambda=2 R$ (for open pore: $\lambda<2 R$ ). In this way, the minimal crack-stress $\sigma$ is only dominated by pore size and pore spacing, which can be evaluated by pore distribution and connectivity. As a result, membrane with close, small, and uniform pore structures shall exhibit high resistance to thermal and external stress. That explains why membrane with fully sponge like cross-sectional morphology shows better mechanical strength than membrane with finger-like macrovoids.

Table S1 Viscosities $\left(20^{\circ} \mathrm{C}\right)$, Van der Waals volumes, solubility parameters of solvents and their Flory-Huggins interaction parameter to PMDA-ODA PAA

\begin{tabular}{lcccccc}
\hline & $\begin{array}{c}\text { Viscosity } \\
(\mathrm{cP})\end{array}$ & $\begin{array}{c}\Delta \mathrm{V} \\
\left(\mathrm{cm}^{3} / \mathrm{mol}\right)\end{array}$ & $\begin{array}{c}\delta_{\mathrm{D}} \\
\left(\mathrm{MPa}^{0.5}\right)\end{array}$ & $\begin{array}{c}\delta_{\mathrm{P}} \\
\left(\mathrm{MPa}^{0.5}\right)\end{array}$ & $\begin{array}{c}\delta_{\mathrm{H}} \\
\left(\mathrm{MPa}^{0.5}\right)\end{array}$ & $\begin{array}{c}\chi_{12} \\
(\mathrm{PAA})\end{array}$ \\
\hline PMDA-ODA PAA & - & 242.7 & 21.0 & 11.9 & 11.0 & - \\
NMP & 1.796 & 96.5 & 18.0 & 12.3 & 7.2 & 0.92 \\
DMF & 0.841 & 77.0 & 17.4 & 13.7 & 11.3 & 0.51 \\
THF & 0.531 & 81.7 & 16.8 & 5.7 & 8.0 & 2.14 \\
IPA & 2.406 & 76.8 & 15.8 & 6.1 & 16.4 & 2.78 \\
GLY & 1412 & 73.3 & 17.4 & 12.1 & 29.3 & 10.3 \\
water & 1.000 & 18.0 & 15.6 & 16 & 42.3 & 7.45 \\
\hline
\end{tabular}




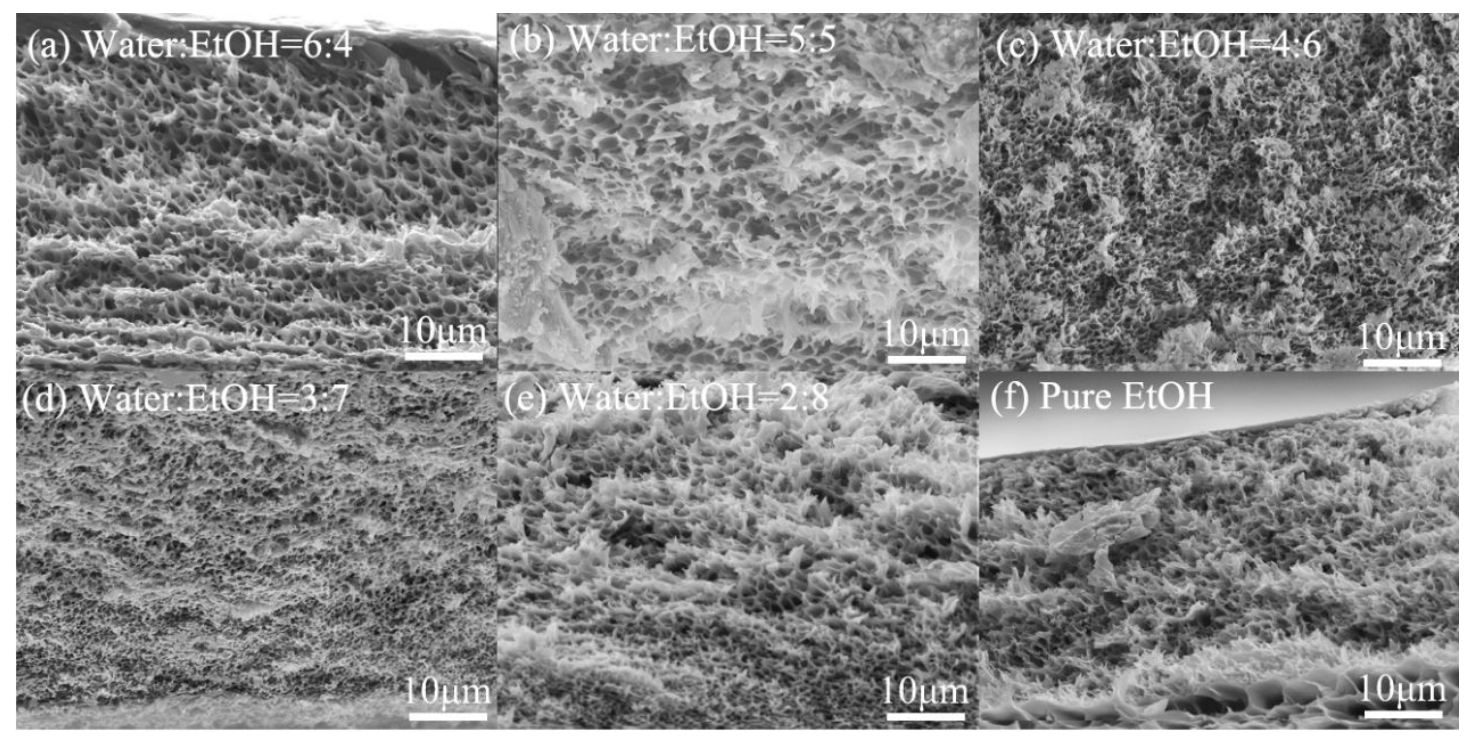

Figure S1 TPI membranes with macrovoid-free structures prepared using PAA/NMP (15/85) dope indifferent coagulant baths: (a) B/4; (b)B/5; (c)B/6; (d) B/7; (e) B/8; (f) B/9.
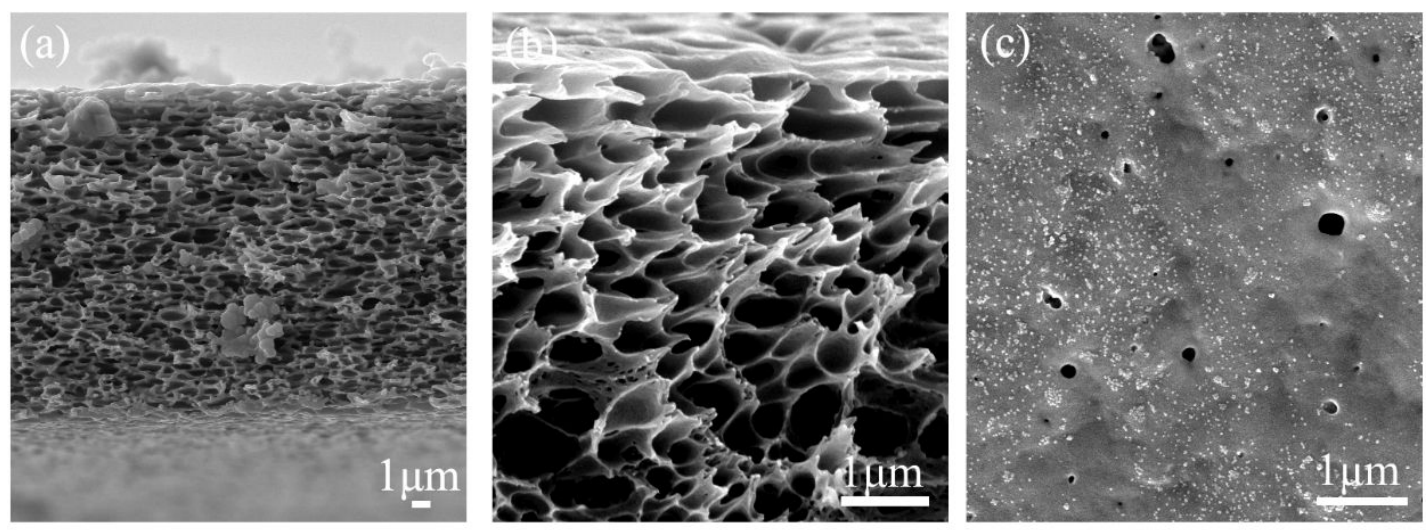

Figure S2 SEM images of A/9 membrane: (a) integral cross-section; (b) top cross-section; (c) top surface.

\section{Reference}

[1] Cadotte, J.; Forester, R.; Kim, M.; Petersen, R.; Stocker, T. Nanofiltration membranes broaden the use of membrane separation technology, Desalination 1988, 70, 77-88.

[2] Kabir, Md E.; Saha, M.C.; Jeelani, S. Tensile and fracture behavior of polymer foams, Mater.

Sci. and Eng. A, 2006, 429, 225-235.

[3] Jung, J. Y. Prediction of tensile ductility in porous materials, Philosophical Magazine A 2002 , 
[4] Rice, R.W. Limitations of pore-stress concentrations on the mechanical properties of porous materials, J. Mater. Sci. 1997, 32, 4731-4736.

[5] Rice, R.W. Relation of Tensile Strength-Porosity Effects in Ceramics to Porosity Dependence of Young's Modulus and Fracture Energy, Porosity Character and Grain Size, Mater. Sci. Eng. A $1989,112,215-224$

[6] Evans, A. G.; Tappin, G. Effects of microstructure on the stress to propagate inherent flaws, Proc. Br. Ceram. Soc. 1972, 20, 275-297.

[7] Boccaccini, A. R.; Ondracek, G.; Mombello, E. Determination of stress concentration factors in porous materials, J. Mater. Sci. Lett. 1995, 14, 534-536. 